\title{
Synthesis, structures and reduction chemistry of monophthalocyanine scandium hydroxides
}

\author{
Yumeela Ganga-Sah, Elahe Tajbakhsh, Rachel H. Platel, ${ }^{\dagger}$ Wen Zhou and Daniel B. \\ Leznoff*
}

Department of Chemistry, Simon Fraser University, 8888 University Drive, Burnaby, B.C, V5A 1S6, Canada

Received date (to be automatically inserted after your manuscript is submitted)

Accepted date (to be automatically inserted after your manuscript is accepted)

\begin{abstract}
The preparation and structural characterization of a pair of scandium(III) phthalocyanine hydroxide complexes were achieved by reaction of $\mathrm{PcScCl}$ with alkali metal alkoxides, likely via hydrolysis of soluble PcSc-alkoxide intermediates. $\mathrm{A} \mathrm{Sc}_{2} \mathrm{Li}_{2}\left(\mu_{3}-\mathrm{OH}\right)_{4}$ cubane supported by two distorted Pc-rings of the form $(\mathrm{PcSc})_{2}\left(\mu_{3}-\mathrm{OH}\right)_{4} \mathrm{Li}_{2}(\mathrm{THF})(\mathrm{DME})$ was isolated from the reaction of $\mathrm{PcScCl}$ with $\mathrm{LiO}^{i} \mathrm{Pr}$, while a simpler alkali-metal free $\left[\mathrm{Pc}_{2} \mathrm{Sc}_{2}\left(\mu_{2}-\mathrm{OH}\right)_{2}(\mathrm{THF})\right]$ was obtained from addition of $\mathrm{NaO}{ }^{t} \mathrm{Bu}$; both structures are reminiscent of bent metallocenes, with dihedral angles between the two Pc-rings of 50.8 and $37.7^{\circ}$ respectively. A soluble $\mathrm{PcScOH}$ material can also be obtained directly via hydrolysis of insoluble $\mathrm{PcScCl}$ in approximately 95:5 THF:water. Reduction of the Pc-ring of $\mathrm{PcScCl}$ using $\mathrm{KC}_{8}$ is reversible and generates $\mathrm{Pc}^{3-}$ and $\mathrm{Pc}^{4-}$-containing materials that were characterized via UV-visible spectroscopy and, where appropriate EPR and ${ }^{1} \mathrm{H}$ NMR spectroscopy; analogous reductions of the PcScOH-based species were irreversible. Exposure of the air-sensitive, reduced $\mathrm{PcScCl}$-based species to ambient atmosphere generated $\mathrm{PcScOH}$ materials analogous to the direct hydrolysis route.
\end{abstract}

KEYWORDS: Scandium, phthalocyanine, hydroxides, crystal structures, ring-reduced phthalocyanines

*Correspondence to: Daniel B. Leznoff, phone 778-782-4887; fax 778-782-3765; email dleznoff@sfu.ca

$\nmid$ Current address: Department of Chemistry, Lancaster University, Lancaster, UK 


\section{INTRODUCTION}

Phthalocyanines are chemically inert, intensely coloured ligands used extensively in industry[1-3]; they have been bound to most metals, but with a very strong focus on later transition-metals. Phthalocyanines are also highly redox-active, with ring oxidation states from $\mathrm{Pc}(-6)$ to $\mathrm{Pc}(0)$ [4-6]. We have been targeting unusual early transition- and f-block metal PcM complexes and their redox chemistry, and have previously reported structurally characterized PcM complexes with early transition-metals $\mathrm{Nb}, \mathrm{Zr}, \mathrm{Cr}$ and $\mathrm{Sc}[7-11]$.

$\mathrm{PcScCl}(\mathbf{1})$ is a potentially interesting starting material for further chemistry of this Lewis-acidic $\mathrm{d}^{0}$ metal centre, however, although it is easily prepared the crude, sparingly soluble $\mathbf{1}$ is invariably contaminated with some (also insoluble) starting reagent $\mathrm{ScCl}_{3}$, requiring a further conversion to $\mathrm{PcScCl}_{2} \mathrm{Li}(\mathrm{THF})_{2}$ (2) using $\mathrm{LiCH}\left(\mathrm{SiMe}_{3}\right)_{2}$ in order to fully purify and solubilize it for further reactivity. Our preliminary studies using 2 utilized $\mathrm{LiCp}$ and $\mathrm{NaCp}^{*}$ as salt metathesis reagents to generate PcScCp and $\mathrm{PcScCp} *$ sandwich complexes (metallophthalocyanin-ocenes)[10]. Overall, there are only a few reported scandium(III) phthalocyanine complexes, including $\mathrm{Pc}_{2} \mathrm{Sc}$-based systems, $\mathrm{PcSc}$ (acetate) and several substituted ScPcX complexes[12-15]; several reports of DFT calculations regarding PcSc-containing species also exist[16-18] and the related Pc-lanthanide(III) species have been more studied[19]. To our knowledge, the only crystal structures of mono-PcSc systems are the aforementioned $\mathrm{PcScCl}_{2} \mathrm{Li}(\mathrm{THF})_{2}$ and the metallophthalocyanin-ocenes[10].

Faced with the limited straightforward entries into PcSc-chemistry, we turned back to the original sparingly soluble crude $\mathrm{PcScCl}$ to investigate whether it could be utilized directly for further chemistry. Reactions with alkali metal alkoxides, structures of the resulting hydroxide products and the ring-reduction reactivity of $\mathrm{PcScCl}$ are all described herein.

\section{RESULTS AND DISCUSSION}

\section{Synthesis, Structural and Spectroscopic Characterization of PcSc hydroxides}

Preparation and solid-state structures. $\mathrm{PcScCl}(1)$ was prepared by the previously reported method of heating $\mathrm{ScCl}_{3}$ and phthalonitrile in 1-chloronaphthalene[10] and utilized as a starting material for salt metathesis reactions targeting the substitution of the chloride with alkoxide functionalities. Accordingly, 1 was suspended in THF and a solution of $\mathrm{LiO}^{i} \mathrm{Pr}$ was added. Gratifyingly, this initiated a rapid solublization of the starting material, which was converted into a soluble dark blue solution characteristic of a PcM complex. Recrystallization from THF/DME afforded dark blue crystals, which were revealed by X-ray crystallography to be not the target alkoxide but instead a PcSc-hydroxide cluster of the form $(\mathrm{PcSc})_{2}\left(\mu_{3^{-}}\right.$ $\mathrm{OH})_{4} \mathrm{Li}_{2}(\mathrm{THF})(\mathrm{DME})(3)$ (Figure 1; Tables 1 and 2), containing two $\mathrm{PcSc}(\mathrm{III})$ units arranged in a tilted "butterfly" fashion (the dihedral angle between the two Pc planes is 50.8 ; Figure S1) and a distorted cubic $\mathrm{Sc}_{2} \mathrm{Li}_{2}\left(\mu_{3}-\mathrm{OH}\right)_{4}$ core, where two hydroxides bridge two scandium and one lithium centre, while the other two hydroxides bridge one scandium and two lithium centres. The cluster is conceptually similar to an "oversized" bent metallocene, with the two Pc-rings taking the place of bis $(\mathrm{Cp})$ units and the cluster representing a metal centre. The two Pc-rings are fairly non-planar (likely for steric reasons), with dihedral angles between adjacent isoindolene units of 30.4, 5.0, 17.0, and 18.2 ${ }^{\circ}$ for Pc-Sc(1) and 23.2, 14.8, 20.7 and $1^{\circ}$ for the second Pc-Sc(2) unit. The Sc(III) centre sits out of the Pc-plane by $1.124 \AA$ for Sc(1) and $1.137 \AA$ for $\mathrm{Sc}(2)$; these figures are higher than in the other mono-PcSc-based structures: $0.93 \AA$ in 2, $0.875 \AA$ in PcScCp and $0.898 \AA$ in PcScCp ${ }^{*}[10]$. The $\mathrm{Sc}(\mathrm{III})$ centres in $\mathbf{3}$ are also more elevated than the $1.067 \AA$ of the $\mathrm{Zr}(\mathrm{IV})$ centre in $[\mathrm{PcZrCl}]_{2}(\mu-\mathrm{Cl})_{2}[9]$. 
Both $d^{0} \mathrm{Sc}$ (III) centres have a seven-coordinate, capped trigonal prismatic geometry[20-21], including the Pc-ring and three $\mu_{3}-\mathrm{OH}$ groups. The Sc-O bond distances (Table 1), spanning 2.169(3)-2.226(3) for the $\mu_{3}-\mathrm{OH}$ units bridging two Sc(III) centres (O1 and $\mathrm{O} 2)$ are slightly longer than for the $\mu_{3}-\mathrm{OH}$ units that are bridging two Li centres $(\mathrm{Sc}(1)-\mathrm{O}(4) 2.096(2)$ and $\mathrm{Sc}(2)-\mathrm{O}(3)$ 2.135(3) ̊̊), but all of which are comparable or slightly longer than Sc-O distances reported for other hydroxidebridged scandium complexes, such as 2.114(2) $\AA$ and 2.183(1) $\AA$ in hydroxynitratoscandium chloride[22] and the 2.076(2) and 2.029(1) $\AA$ in $[(\mathrm{OEP}) \mathrm{ScOH}]_{2}(\mathrm{OEP}=$ octaethylporphyrin) $[23-24]$.

$<$ FIGURE \#1>

$<$ TABLE \#1>

$<$ TABLE \#2>

In a similar fashion, the reaction of sparingly soluble $\mathbf{1}$ in $\mathrm{THF}$ with $\mathrm{NaO}^{t} \mathrm{Bu}$ at room temperature under nitrogen for 48 hours generated a deep blue solution. Recrystallization from THF/DME afforded dark blue crystals not of the alkoxide but of $(\mathrm{PcSc})_{2}(\mu-\mathrm{OH})_{2}(\mathrm{THF})(4)$ (Figure 2; Tables 3 and 4), a simpler dinuclear PcSc hydroxide with two bridging hydroxides but lacking the additional alkali metal cations present in 3 . Thus, the Li cation delivered by the $\mathrm{LiO}^{i} \mathrm{Pr}$ reagent was retained in the final solid-state "ate-complex" cluster 3, while the $\mathrm{Na}$ cation associated with the $\mathrm{NaO}^{t} \mathrm{Bu}$ was not incorporated in the cluster 4; this trend is commonly observed in early-transition metal and f-block structural chemistry. The two scandium centres are different: $\mathrm{Sc}(1)$ has a six-coordinate, trigonal prismatic geometry comprised of the Pc-ring and two bridging $\mathrm{OH}-$ groups, while $\mathrm{Sc}(2)$ has an additional bound THF, generating a seven-coordinate capped trigonal prismatic geometry. The $\mathrm{Sc}(\mathrm{III})$ centres are less displaced from the Pc-ring in 4 compared to 3, with displacements of $0.957 \AA$ for $\operatorname{Sc}(1)$ and $1.084 \AA$ $\mathrm{Sc}(2)$; these are still larger than the $0.84 \AA$ displacement of the $\mathrm{Sc}(\mathrm{III})$ centre in the related $\left\{[\mathrm{OEP}] \mathrm{Sc}\left(\mu_{2}-\mathrm{OH}\right)\right\}_{2} \operatorname{system}[23]$. The dihedral angles between adjacent isoindolenes for the $\mathrm{Pc}-\mathrm{Sc}(1)$ unit are 8.9, 15.6, 5.9 and $20.9^{\circ}$ and 5.2, 16.2, 19.6, $15.9^{\circ}$ for the $\mathrm{Pc}-\mathrm{Sc}(2)$ unit; both are less distorted than in $\mathbf{3}$, reflecting the lower steric strain in 4 . This is also apparent in the lower dihedral angle of $37.7^{\circ}$ between the two phthalocyanine rings in $\mathbf{4}$ compared with $\mathbf{3}$, although the general "butterfly" shape of the overall cluster is still maintained (Figure S1). The Sc-OH bond lengths are generally shorter than in 2, consistent with $\mu_{2}$ vs. $\mu_{3}$ bridging, ranging from 2.056(3)-2.129(3) A (Table 3).

$<$ FIGURE \#2>

$<$ TABLE \#3>

$<$ TABLE \#4>

Solution behaviour. Although the solid-state structures of $\mathbf{3}$ and $\mathbf{4}$ are multinuclear clusters, their solution-state structures appear to be more dynamic, which is unsurprising given that the solid-state structures include specific amounts of bound solvent and (for 3) additional complexed $\mathrm{LiOH}$, all of which have the potential to dissociate in solution. For example, the MALDI-TOF mass spectrum of 3 has a strong signal at $\mathrm{m} / \mathrm{z} 1145$, corresponding to $\left.\left[(\mathrm{PcSc})_{2}(\mu-\mathrm{OH})_{2}-3 \mathrm{H}\right)\right]^{+}$; M+ peak for the complete Li-"ate" complex cluster was not observed. The UV-visible spectrum of 3 dissolved in THF shows $\lambda_{\max }$ of 669,628 and $339 \mathrm{~nm}$ but in toluene $\lambda_{\max }$ values are $676,634 \mathrm{sh}, 611$ sh and 340 . The ${ }^{1} \mathrm{H}$ NMR spectrum of 3 was acquired in non-deuterated THF using the (Multiple) Solvent Suppression WET technique[25-26], where four broad signals of approximately equal integration were observed at 9.29, 9.12, 8.09 and $7.88 \mathrm{ppm}$, which suggests the presence of 
more than one species in solution; these could include (for example) a THF- or water-solvated hydroxo-bridged dimer and/or a more highly solvated monomeric PcSc-OH system species, but does not correspond to the asymmetric solid-state structure of $\mathbf{3}$, implying that cluster at least likely loses LiOH in THF solution. The ${ }^{1} \mathrm{H}$ NMR spectrum of $\mathbf{3}$ in (noncoordinating) toluene- $d_{8}$ with minimal THF solvent (for solubility) is composed of two main peaks at 9.30 (dd, $J=3,6 \mathrm{~Hz}$, $8 \mathrm{H})$ and $7.90(\mathrm{dd}, J=3,6 \mathrm{~Hz}, 8 \mathrm{H}) \mathrm{ppm}$, and two minor peaks at $9.23(\mathrm{~m}, 1 \mathrm{H})$ and $7.83(\mathrm{~m}, 1 \mathrm{H}) \mathrm{ppm}$, suggesting the presence of a major and minor species, where the major species corresponds to one of the structures in THF. A resonance assignable to the Sc-OH proton could not be readily determined.

In the case of 4 , the MALDI-TOF mass spectrum of the crude sample has a signal at $1237.66\left[(\mathrm{PcSc})_{2}(\mu-\mathrm{OH})_{2}+(4 \mathrm{Na}-\right.$ $3 \mathrm{H})]^{+}$. The UV-vis spectrum of crystals of 4 dissolved in THF initially is $\lambda_{\max }=679,636$ and 341 but changes slightly over several minutes to $\lambda_{\max }=677,648 \mathrm{sh}, 613,343 \mathrm{~nm}$, indicating that the initial dissolved material slightly changes structure in solution over time; in toluene, the $\lambda_{\max }$ are similar to the initially observed spectrum in THF. The ${ }^{1} \mathrm{H}$ NMR spectrum of the crystals in THF is similar to that of $\mathbf{3}$, showing two major signals at 9.46 (dd, $J=3,5 \mathrm{~Hz}, 12 \mathrm{H}$ ) and $8.16(\mathrm{dd}, J=3,6 \mathrm{~Hz}$, $12 \mathrm{H})$ ppm and two minor peaks at $9.17(\mathrm{~m}, 4 \mathrm{H})$ and $8.11(\mathrm{~m}, 4 \mathrm{H}) \mathrm{ppm}$. In toluene- $d_{8}$ with minimal THF, only two sharp peaks of equal integration were observed at 9.28 and $7.91 \mathrm{ppm}$, suggesting a more highly symmetric structure consistent with a solvate-free PcSc-system; these peaks also correspond to the major pair of peaks found in the toluene- $d_{8}$ spectrum of $\mathbf{3}$, suggesting that both complexes generate identical structures in toluene solution prior to their precipitation. Indeed, the spectra of both complexes in toluene are further complicated by the fact that within 5-10 minutes of THF-assisted dissolution dark blue precipitate starts forming, even at fairly low concentrations, and thus the final (likely solvate-free) material is ultimately insoluble in toluene/trace THF. Taken together, the high symmetry of the system, its MALDI-MS data, and its tendency to aggregate to an insoluble precipitate is consistent with a tentative structural assignment of solvatefree $[\mathrm{PcSc}(\mu-\mathrm{OH})]_{2}$. Further efforts to conclusively structurally characterize this material are in progress; a similar solvatefree structure for $\left\{[\mathrm{OEP}] \mathrm{Sc}\left(\mu_{2}-\mathrm{OH}\right)\right\}_{2}$ suggests that such a structure is accessible and reasonable for the phthalocyanine analogue[23-24].

Overall, it is clear that the solid-state structures of $\mathbf{3}$ and $\mathbf{4}$ are not maintained in solution over time, and the structures change depending on whether they contain coordinating solvents or not; such binding can occur at both the scandium centre and via with any accompanying salts (e.g. $\mathrm{LiOH}$ in 3). A detailed study of the structures and any associated solution equilibria thereof for $\mathbf{3}$ and $\mathbf{4}$ is further complicated by the limited solubility of the species in non-coordinating solvents and thus was not pursued further.

Direct hydrolysis of 1 . It was unclear whether the putative alkoxide complex formed and then subsequently decomposed via hydrolysis from water of $\mathrm{ScCl}_{3} \bullet \mathrm{nH}_{2} \mathrm{O}$ (present as an impurity in the preparation of $\mathbf{1}$ )[10] or if $\mathbf{1}$ reacted directly with water. In an effort to explore this, reagent grade, non-dry THF (which contains comparable or greater levels of moisture than the $\mathrm{ScCl}_{3} \bullet \mathrm{nH}_{2} \mathrm{O}$ impurity) was added to $\mathbf{1}$ in ambient atmosphere. Under these conditions, $\mathbf{1}$ remained as an insoluble suspension - unlike the immediate solublization observed upon addition of either LiO ${ }^{\mathrm{i}} \mathrm{Pr}$ or NaO'Buto 1 in dry THF - which strongly suggests that soluble PcSc-alkoxides were indeed generated, which then slowly hydrolyzed to give the final observed crystalline hydroxide products 3 and 4 . Utilization of 2 or the complete dehydration of the $1 / \mathrm{ScCl}_{3} \cdot \mathrm{xH}_{2} \mathrm{O}$ mixture (or removal of the salt completely) would likely obviate this issue and allow for the isolation of the PcSc-alkoxide; these routes are currently under investigation.

Critically, although 1 is insoluble in THF, the addition of significant amounts of water - approximately $5 \%$ (by volume) to this suspension resulted in the rapid solublization of the material and formation of a green solution with several 
absorption maxima $\left(\lambda_{\max }=674,653 \mathrm{sh}, 609,339 \mathrm{~nm}\right)$, which appears nearly identical to the UV-visible spectrum obtained from waiting several minutes after dissolving 4 in THF, suggesting that the same PcScOH-containing species (but not corresponding to the solid-state structure of 4) results from both routes. Thus, importantly, PcScOH-type species can indeed be accessed directly by hydrolysis of $\mathbf{1}$ in wet THF, without resorting to the use of alkali metal alkoxides.

Addition of $\mathrm{LiOH}$ to this solution in an effort to prepare $\mathbf{3}$ via this alternative route generated a blue solution, with several different absorption maxima $\left(\lambda_{\max }=666,624 \mathrm{sh}, 609,364 \mathrm{sh}, 336 \mathrm{~nm}\right)$ as well as some insoluble precipitate; this is all consistent with the formation of a mixture of related products, possibly including $\mathbf{3}$, in solution upon addition of LiOH but we did not isolate any pure complex from this reaction.

\section{Reduction Chemistry}

Whereas axial substitution of an MPc causes almost no change to the UV-visible spectrum since the transitions due to the ligand have extremely large molar absorptivity coefficients, a change in the oxidation state of the Pc-ring causes significant changes to the absorption spectrum of a given PcM species[6]. These have been studied extensively in solution across the full range of oxidation states the Pc ligand can access (0 to -6$)[5,6,27]$. Since scandium itself is both diamagnetic and redox inactive, only Pc-ring reduction should be observed, simplifying the analysis compared to the systems with redox-active metals.

Reduction Chemistry of 1 . The previously reported CV of $\mathbf{1}$ showed reduction peaks at -0.78 and $-1.10 \mathrm{~V}$ in THF (vs. $\mathrm{Ag} / \mathrm{AgCl}$ ). Accordingly, reduction of $\mathbf{1}$ was undertaken using one, two and three equivalents of $\mathrm{KC}_{8}$ in THF or DME (no reaction occurred in toluene due to the complete insolubility of both reagents therein). Upon addition of solid $\mathrm{KC}_{8}$ to suspensions of $\mathbf{1}$ in THF, colour changes in the reaction mixtures as well as a dramatic increase in solubility of the Pc derivative were observed within a few seconds. Addition of 1 equivalent of $\mathrm{KC}_{8}$ to 1 caused the immediate formation of a purple solution, which turned royal blue over 10-20 seconds, while addition of 2 and 3 equivalents of $\mathrm{KC}_{8}$ gave solutions that were bright purple in colour and maintained this appearance. By UV-visible spectroscopy, the royal-blue material obtained from the putative one-electron reduction (i.e., $\mathbf{1}^{-}$) is clearly a mixture (Figure S3), with $\lambda_{\max }$ peaks typical of both a $\mathrm{Pc}^{3-}$ ligand $(656,570 \mathrm{~nm})$ and also a doubly-reduced $\mathrm{Pc}^{4-}$ ring (i.e., $\left.\mathbf{1}^{2-}\right)(495 \mathrm{~nm})$, in addition to some unreacted $\mathbf{1}(674,605$ $\mathrm{nm}$ ), similar to what was observed for the analogous reaction with $\mathrm{PcZrCl}_{2}[9]$. The fact that both $\mathbf{1}$ and $\mathrm{KC}_{8}$ are insoluble in THF and DME, and the fact that initial reduced product $\mathbf{1}^{-}$is more soluble than $\mathbf{1}$, generates challenges for the generation (or isolation) of exclusively the one-electron reduced species $\mathbf{1}^{*}$, since the soluble, reduced $\mathbf{1}^{-}$reacts faster with residual $\mathrm{KC}_{8}$ than with $\mathbf{1}$, generating the observed mixture of $\mathbf{1}^{-}$and $\mathbf{1}^{2-}$ (containing $\mathrm{Pc}^{3-}$ and $\mathrm{Pc}^{4-}$ rings respectively).

The spectra of the species obtained from two and three equivalents of $\mathrm{KC}_{8}$ are very similar, with $\lambda_{\max }$ values of 510 and $324 \mathrm{~nm}$, consistent with the generation of doubly-reduced a $\mathrm{Pc}^{4-}$ ring (i.e., $\mathbf{1}^{\mathbf{2}}$ ); increasing levels of $\mathrm{KC}_{8}$ generates purer $\mathbf{1}^{\mathbf{2}-}$ (Figures 3 and S4). These values are very similar to those published for other $\mathrm{Pc}^{4-}$ systems: $\left[\mathrm{Pc}^{4-} \mathrm{Zn}\right]^{2-}\left(\lambda_{\max } 522,335 \mathrm{~nm}\right)$ and $\left[\mathrm{Pc}^{4-} \mathrm{Mg}\right]^{2-}\left(\lambda_{\max } 520,335 \mathrm{~nm}\right)[28]$, as well as a $\left[\mathrm{Pc}^{4-} \mathrm{NbO}\right]^{2-}$ species $(521 \mathrm{~nm})[11]$. It is unclear if the third equivalent of $\mathrm{KC}_{8}$ has effected any reaction beyond ensuring complete conversion to $\mathbf{1}^{2-}$; clearly a triply-reduced $\mathrm{Pc}^{5-}$ ring is not the final result.

$<$ FIGURE \#3> 
It was not possible to obtain mass spectra of the reduced species $\mathbf{1}^{-}$and $\mathbf{1}^{\mathbf{2}}$ due to their extreme sensitivity to very small amounts of oxygen or moisture. Indeed, upon exposure to air, the oxidation of solutions of the reduced products is rapid, with an instantaneous colour change from blue or purple to turquoise. Similarly, the addition of ferrocenium tetrafluoroborate under an inert atmosphere causes the same colour change over the course of a few minutes; the resulting isolated turquoise powders were analyzed by UV-visible spectroscopy and MALDI-TOF mass spectrometry. The UV-

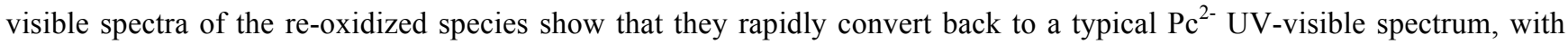
$\lambda_{\max }$ values of 674,605 and $339 \mathrm{~nm}$, very similar to the signature of the aforementioned species obtained from either the direct hydrolysis of $\mathbf{1}$ or the dissolution and decomposition of $\mathbf{4}$ in wet THF (Figure 3), consistent with a PcScOH-type product. The MALDI-TOF-MS spectra of the oxidized products indicate that both reduced species of $\mathbf{1}$ do indeed decompose to $\mathrm{PcScOH}(\mathrm{m} / \mathrm{z} 576)$, presumably by reaction with both ambient water and oxygen, consistent with the aforementioned UV-visible spectroscopic data. The mass spectra also contain a signal at $\mathrm{m} / \mathrm{z} 1171$, corresponding to $\left[(\mathrm{PcSc})_{2} \mathrm{KOH}\right]^{+}$. Similar decomposition products from scandium, yttrium and lutetium octaethylporphyrin complexes yielded species of the form $[(\mathrm{OEP}) \mathrm{M}(\mu-\mathrm{OH})]_{2}(\mathrm{M}=\mathrm{Sc}, \mathrm{Y}, \mathrm{Lu})[23,29]$.

Conducting these reductions in bulk in an effort to isolate crystals, stirring $\mathbf{1}$ and $\mathrm{KC}_{8}$ (one, two and three equivalents) at ambient temperature, followed by filtration through celite to remove carbon and removal of solvent yielded impure $\mathbf{1}^{-}$as a red/blue/purple dichroic powder in $72 \%$ yield and $\mathbf{1}^{2-}$ as a purple/gold/green dichroic powder in $73 \%$ and $84 \%$ yields for one, two and three equivalents of $\mathrm{KC}_{8}$ respectively. Exhaustive attempts were made to grow crystals of a suitable size and quality for X-ray diffraction. In the case of $\mathbf{1}^{-}$, the mixture was resistant to crystallization from THF, hexane, toluene and mixtures of these solvents, forming films over long periods of time. Crystals of $\mathbf{1}^{2-}$ were grown from a THF/hexanes mixture; however, they diffracted extremely weakly/poorly and a structure could not be obtained. Thus, in the absence of any solid-state structural data, we sought to characterize these species in the solution-state using additional spectroscopic methods.

The use of diamagnetic $\mathrm{d}^{0} \mathrm{Sc}(\mathrm{III})$, coupled with the fact that reduction led to compounds that were fully soluble in THF, facilitated the acquisition of both ${ }^{1} \mathrm{H}$ and ${ }^{13} \mathrm{C}\left\{{ }^{1} \mathrm{H}\right\}$ NMR spectra in THF- $d_{8}$ for the reduced species, which can be compared to the soluble $\mathrm{PcSc}\left(\mu-\mathrm{Cl}_{2}\right) \mathrm{Li}(\mathrm{THF})_{2}$, which contains a $\mathrm{Pc}^{2-}$ ligand. Compound $\mathbf{1}^{-}$is NMR silent, which is unsurprising given that $\mathrm{Pc}^{3-}$ rings are radical anions[30-35]. Given this paramagnetic nature of $\mathbf{1}^{-}$, an EPR spectrum was collected at $77 \mathrm{~K}$ in THF (Figure 4). It showed two signals, with $\mathrm{g}=2.003$ and 1.994 but no hyperfine splitting, confirming the presence of an unpaired ring-electron in $\mathbf{1}^{-}$. The presence of two signals is consistent with a mixture of radical-containing products, which may feature aggregation of $\mathbf{1}^{-}$with either $\mathbf{1}^{\mathbf{2}}$ or residual $\mathbf{1}$ (as supported by the UV-visible data); such mixed-valent aggregated species and their similar EPR spectra were recently reported in detail for a ring-oxidized PcZn-based system[36].

\section{$<$ FIGURE \#4>}

The ${ }^{1} \mathrm{H}$ NMR spectrum of $\mathbf{1}^{2-}$ contains just two sharp multiplet resonances of equal integration at 5.20 and 4.16 ppm, corresponding to the protons on the Pc ring (Figure 5). These are shifted significantly upfield compared to typical Pc ${ }^{2-}$ ligand resonances, e.g., 9.53 and $8.24 \mathrm{ppm}$ in $\mathrm{PcSc}\left(\mu-\mathrm{Cl}_{2}\right) \mathrm{Li}(\mathrm{THF})_{2}(2)$. This upfield shift for the Pc ring proton resonances in $\mathbf{1}^{\mathbf{2}}$, to the region where non-aromatic alkene proton signals are found, reflect the partial loss of aromaticity in the Pc ring 
as it is reduced from an $18 \pi$-electron aromatic $\mathrm{Pc}^{2-}$ ligand to a $20 \pi$-electron antiaromatic $\mathrm{Pc}^{4-}$ species; this spectroscopic feature has been similarly reported for the doubly ring-reduced $\mathrm{PcGe}(\mathrm{py})_{2}[33]$ and $(\mathrm{OEt})_{8} \mathrm{PcMnN}[37]$.

$<$ FIGURE \#5>

Reduction of 3 and 4. The $\mathrm{CV}$ of 3 in DMSO shows two ring-reduction $\left(\mathrm{Pc}^{2-} / \mathrm{Pc}^{3-}\right)$ waves at $-1.29 \mathrm{~V}$ and $-1.62 \mathrm{~V}$ vs. ferrocene (and a ring-oxidation wave for $\mathrm{Pc}^{-2} / \mathrm{Pc}^{-1}$ at $1.14 \mathrm{~V}$ ), while 4 has two ring-reduction waves at $-1.37 \mathrm{~V}\left(\mathrm{Pc}^{2-} / \mathrm{Pc}^{3-}\right)$ and $-1.58 \mathrm{~V}\left(\mathrm{Pc}^{3-} / \mathrm{Pc}^{4-}\right)$, and a single oxidation wave at $1.15 \mathrm{~V}$, however in all cases, the waves are irreversible and much less clean than for $\mathbf{1}$; the second reduction waves in particular do not correspond to a reduction of the same structural unit as the first reduction and must be considered with caution. Sufficient quality CV data for $\mathbf{3}$ and $\mathbf{4}$ could not be obtained in THF, and thus a direct comparison with $\mathbf{1}$ is difficult, however, the data suggests that $\mathbf{1}$ is slightly easier to reduce (and the reduction products clearly are more stable from the CV perspective) than both $\mathbf{3}$ and $\mathbf{4}$, and the first reduction potential for $\mathbf{3}$ is slightly lower than for 4 .

With these stability issues in mind, reduction of $\mathbf{3}$ was carried out using various amounts (1-2 equivalents per Pc ring) of both $\mathrm{KC}_{8}$ and the milder, soluble reducing agent $\mathrm{KBEt}_{3} \mathrm{H}$ in $\mathrm{THF}$ at room temperature[8, 9, 28]. Treatment with excess $\mathrm{KBEt}_{3} \mathrm{H}$ eventually (after 50 hours) generated a royal-blue solution $\left(\lambda_{\max }=577 \mathrm{~nm}\right)$ consistent with the formation of a Pc ${ }^{3-}$ unit. Reduction with 2.5 equivalents of $\mathrm{KC}_{8}$ instantly gave a purple solution with broad $\lambda_{\max }$ at 534 and $572 \mathrm{~nm}$, consistent with a mixture of $\mathrm{Pc}^{4-}$ and $\mathrm{Pc}^{3-}$ species respectively. As for $\mathbf{4}$, no reduction was observed upon addition of 4 equivalents of $\mathrm{KBEt}_{3} \mathrm{H}$ after 12 hours, and even after 50 hours, only a small amount of the $\mathrm{Pc}^{3-}$ species $\left(\lambda_{\max }=572 \mathrm{~nm}\right)$ was detected along with unreacted 4. Using 2.5 equivalents of $\mathrm{KC}_{8}$ (per Pc-ring unit), a peak at $572 \mathrm{~nm}$ together with a peak at $672 \mathrm{~nm}$ were seen, suggesting a mixture of $\mathrm{Pc}^{3-}$ and $\mathrm{Pc}^{2-}$ species. None of these species were isolated and further study of these unstable reduced products was not pursued.

\section{CONCLUSIONS}

It is clear that the insoluble $\mathrm{PcScCl}$ can indeed be used as a starting material for further chemistry, but unless it is separated from the accompanying $\mathrm{ScCl}_{3} \bullet \mathrm{xH}_{2} \mathrm{O}$ then $\mathrm{PcScOH}$-based materials - which are interesting in their own right - are ultimately isolated. The direct hydrolysis of $\mathrm{PcScCl}$ in $\mathrm{THF} /$ water readily generates a soluble $\mathrm{PcScOH}$ system; this solubility is somewhat unusual given that the phthalocyanine ring is unsubstituted (and thereby lacks solubilizing groups) and the axial hydroxide is prone to forming intermolecular hydrogen bonding interactions, in addition to the typical pi-pi stacking aggregation often observed with PcM systems. The structural chemistry of PcScOH-containing systems prepared via the alkoxide/hydrolysis route provides insight into this solubility: the structures reflect the incorporation of available donor solvent and $\mathrm{LiOH}$ (in the case of the $\mathrm{LiO}^{i} \mathrm{Pr}$ reagent) into the fundamental $\mathrm{PcScOH}$ framework, both of which change the $\mathrm{PcScOH}$ structure from the typical disk-shape to more complex non-planar clusters that are reminiscent of bent metallocenes, thereby limiting the ability of the Pc-rings to aggregate and presumably greatly increasing solubility of the system. Similar non-planar, solvated $\mathrm{PcScOH}$ structures that break up aggregation and increase solubility are likely generated upon the direct hydrolysis of $\mathrm{PcScCl}$. Overall, the solubility of $\mathrm{PcScOH}$-containing systems readily opens the door to further exploring their chemistry moving forward. Complete dehydration of the $\mathrm{PcScCl} / \mathrm{ScCl}_{3} \cdot \mathrm{xH}_{2} \mathrm{O}$ mixture or 
ideally, removal of the $\mathrm{ScCl}_{3}$ completely should allow for isolation of the alkoxide intermediates and also for broader substitution chemistry of $\mathrm{PcScCl}$ to proceed.

\section{EXPERIMENTAL SECTION}

\section{General Procedures and Materials}

All techniques and procedures were carried out under a nitrogen atmosphere either with an Mbraun 130 glovebox or using standard Schlenk and vacuum-line techniques. All glassware was dried overnight at $160{ }^{\circ} \mathrm{C}$ prior to use. $\mathrm{PcScCl}$ (1) $[10]$ and $\mathrm{KC}_{8}[38]$ were prepared using previously reported procedures. All other chemical reagents were analytical grade or better, and were purchased from Sigma-Aldrich unless stated otherwise, and used without further purification. Toluene, tetrahydrofuran (THF), and 1,2-dimethoxyethane (DME) were distilled from a sodium/benzophenone solution under nitrogen. Hexanes were distilled from sodium under nitrogen. Deuterated solvents were freeze-pump-thawed three times, refluxed over sodium/benzophenone, and vacuum transferred to a dry bomb for storage prior to use. ${ }^{1} \mathrm{H}$ NMR, and ${ }^{13} \mathrm{C}$ NMR were acquired at $299 \mathrm{~K}$ unless specified otherwise on either a Bruker Avance III 400 spectrometer (400 MHz), Bruker Avance III 500 spectrometer (500 MHz) or Bruker Avance II 600 spectrometer equipped with a QNP cryoprobe. Deuterated toluene and THF were used as solvent and internal reference. ${ }^{1} \mathrm{H}$ NMR spectra of $\mathbf{3}$ and $\mathbf{4}$ were acquired on a Bruker Avance II 600 spectrometer equipped with a QCI cryoprobe using 1) toluene- $d_{8}$, and 2) THF with (Multiple-) Solvent Suppression WET techniques[25-26] with THF as the solvent and internal reference. Chemical shifts $(\delta)$ are given in parts-per-million $(\mathrm{ppm})$. Electronic spectra were recorded on a Cary 5000 spectrophotometer at $20{ }^{\circ} \mathrm{C}$. Solutions of concentration lower than $0.2 \mathrm{mM}$ were analyzed in a $0.1 \mathrm{~cm}$ quartz UV-vis cell. UV-vis data of all ring-reduced species were acquired in the glovebox using Ocean Optics UV-Vis-NIR DT-MINI-2-GS Spectrometer equipped with a deuterium tungsten halogen light source, and processed using SpectraSuite ${ }^{\circledR}$ Spectrometer Operating Software. X-band EPR data were recorded using a Bruker EMXplus spectrometer with a PremiumX microwave bridge and HS resonator at 77K.

Matrix-assisted laser desorption ionization time-of-flight mass spectrometry (MALDI-TOF-MS) data were collected with a Bruker Autoflex Speed spectrometer (Bruker Daltonics, Bemen, Germany) equipped with a 1kHz Smartbeam-II laser. Positive-ion mass spectra were acquired typically within $\mathrm{m} / \mathrm{z}, 300-7000$ range. The mass spectrometer was operated in the reflection mode, and the mass spectrum obtained for each image position corresponds to the average mass spectra of a minimum of 5000 consecutive laser shots. Elemental analyses $(\mathrm{C}, \mathrm{H}, \mathrm{N})$ were performed at Simon Fraser University by Dr. Wen Zhou on a Carlo Erba 1110 CHN elemental analyzer.

All cyclic voltammetry $(\mathrm{CV})$ experiments were conducted using CHInstruments 6171B potentiostat in a dry quartz cell, using a $3 \mathrm{~mm}$ basal-plane pyrolytic graphite electrode (BPG) as working electrode, platinum counter electrode, and $\mathrm{Ag}$ reference electrode. Working solutions comprised $5 \mathrm{~mL}$ of electrolyte solution containing dimethyl sulfoxide (DMSO) with $0.1 \mathrm{M}$ tetrabutylammonium perchlorate $\left(\left[\mathrm{TBA}^{+}\right]\left[\mathrm{ClO}_{4}{ }^{-}\right]\right)$and $0.5 \mathrm{mM}$ of $\mathbf{3}$ and $\mathbf{4}$, which were degassed with argon for 20 min and kept under a positive pressure of argon during the experiment. All CV experiments were referenced to the ferrocenium/ ferrocene couple $\left(\mathrm{Fc}^{+} / \mathrm{Fc}\right)$ by dissolving $\sim 0.1 \mathrm{mg}$ of ferrocene into the supporting electrolyte and performing a $\mathrm{CV}$ to obtain the reference potential. The working electrode was polished after every CV measurement with sand paper and alumina in water and rinsed with acetone followed by using air flow to dry it. It was sonicated in acetonitrile to remove particulates, and dried by a heat gun before use. 
Single-Crystal X-ray Diffraction. Suitable crystals of 3 and 4 were covered with Paratone oil in a glovebox under an $\mathrm{N}_{2}$ atmosphere, transferred, and mounted on a MiTe-Gen sample holder, and placed in the cold stream (150 K) of the diffractometer. The temperature was regulated to $150 \mathrm{~K}$ using an Oxford Cryosystems Cryostream. Device. All data was collected using a Bruker SMART equipped with an APEX II CCD area detector and graphite monochromated $\mathrm{Cu} \mathrm{K} \alpha(\lambda=$ $1.54178 \AA$ A) radiation. All diffraction data were processed with the Bruker Apex II software suite. All structures were solved with intrinsic phasing method and subsequent refinements were performed using ShelXle[39]. Data were collected and integrated using the Bruker SAINT software package and were corrected for absorption effects using the multi-scan technique (SADABS[40] or TWINABS[41]). Diagrams were prepared using ORTEP-3[42] and rendered using POVRay[43]. The electron density peaks (Q-peaks) for the hydroxide hydrogen atoms were found and refined, while the others were geometrically placed and refined accordingly. Additional crystallographic information can be found in Table 5 and in CCDC \#1959481 and 1959482 deposited with the Cambridge Structural Database.

\section{Synthetic Procedures}

Synthesis of (PcSc) $)_{2}\left(\mu_{3}-\mathrm{OH}\right)_{4} \boldsymbol{L i}_{2}(\mathrm{THF})(\mathrm{DME})$ (3). PcScCl (35 mg, $\left.0.059 \mathrm{mmol}\right)$ was suspended in THF and one equivalent of $\mathrm{LiO}^{i} \operatorname{Pr}\left(0.06 \mathrm{~mL}\right.$ of $1 \mathrm{M}$ of $\mathrm{LiO}^{i} \mathrm{Pr}$ in THF, $\left.0.059 \mathrm{mmol}\right)$ was added dropwise. The reaction mixture turned to a soluble dark blue solution. Stirring at room temperature was continued for 48 hours, after which the mixture was filtered over Celite. The THF was removed in vacuo to give a deep blue solid which was extracted with hexanes, toluene, and THF in that order; a majority of the coloured material was retained in the toluene fraction. The toluene was removed in vacuo and recrystallized from DME/THF to give dark blue block crystals of $(\mathrm{PcSc})_{2}\left(\mu_{3}-\mathrm{OH}\right)_{4} \mathrm{Li}_{2}(\mathrm{THF})(\mathrm{DME})(3)(22 \mathrm{mg}, 81 \%$ yield). ${ }^{1}$ H NMR (600 MHz, THF) d: 9.29 (m, 5 H), 9.12 (m, 4 H ), 8.10 (m, 5 H), 7.88 (m, 6 H) ppm. UV-vis (THF): $\lambda_{\max } 339,628$, $669 \mathrm{~nm}$. MALDI-TOF MS: $\left.1145\left[(\mathrm{PcSc})_{2}(\mu-\mathrm{OH})_{2}-3 \mathrm{H}\right)\right]^{+}$.

Synthesis of $(\boldsymbol{P c S c})_{2}(\boldsymbol{\mu}-\mathrm{OH})_{2}(\mathrm{THF})(4) . \mathrm{PcScCl}(50 \mathrm{mg}, 0.084 \mathrm{mmol})$ was suspended in THF and one equivalent of $\mathrm{NaO}^{t} \mathrm{Bu}(8.1 \mathrm{mg}, 0.084 \mathrm{mmol})$ was added as a solid. The reaction mixture turned to a soluble dark blue solution. Stirring at room temperature was continued for 48 hours, after which the mixture was filtered over celite. The THF was removed in vacuo to give a deep blue solid which was purified by extraction with hexanes, toluene, and THF respectively. The THF fraction contained the majority of coloured material and upon removal of the solvent, blue $(\mathrm{PcSc})_{2}(\mu-\mathrm{OH})_{2}(\mathrm{THF})(\mathbf{3})$ was obtained $\left(33.6 \mathrm{mg}, 65 \%\right.$, based on formation of $\left.(\mathrm{PcSc})_{2}(\mu-\mathrm{OH})_{2}(\mathrm{THF})\right)$; dark blue block crystals of 3 were obtained from recrystallization of a THF solution at a hexanes interface layer. ${ }^{1} \mathrm{H}$ NMR $(600 \mathrm{MHz}$, THF) $\delta: 9.46(\mathrm{dd}, J=3,5 \mathrm{~Hz}, 12 \mathrm{H})$, $9.17(\mathrm{~m}, 4 \mathrm{H}), 8.16(\mathrm{dd}, \mathrm{J}=3,6 \mathrm{~Hz}, 12 \mathrm{H}), 8.11(\mathrm{~m}, 4 \mathrm{H}) \mathrm{ppm}$. UV-Vis (THF) $\lambda_{\max }=341,636,679$. MALDI-TOF MS (m/z): $537.14\left[\left(\mathrm{PcH}_{2}+\mathrm{Na}\right)^{+}\right]$and $1237.66\left[(\mathrm{PcSc})_{2}(\mu-\mathrm{OH})_{2}+(4 \mathrm{Na}-3 \mathrm{H})\right]^{+}$.

Reduction of PcScCl (1) with 1 equivalent of $\mathrm{KC}_{8} . \mathrm{PcScCl}(0.120 \mathrm{~g}, 0.203 \mathrm{mmol})$ was added as a solid to a stirred suspension of $\mathrm{KC}_{8}(0.030 \mathrm{~g}, 0.223 \mathrm{mmol} ; 10 \%$ excess $)$ in DME $(5 \mathrm{~mL})$. The residue was rinsed into the reaction mixture with DME $(5 \mathrm{~mL})$. The reaction mixture was stirred at ambient temperature overnight. The bright blue reaction mixture was filtered through celite and the solid residue rinsed with DME $(3 \times 5 \mathrm{~mL})$. The solvents were removed from the filtrate in vacuo to leave an iridescent blue/purple solid $(0.090 \mathrm{~g}, 72 \%)$. EPR (THF, $77 \mathrm{~K})$ : g = 2.003 and 1.994; UV-vis: (DME) $\lambda_{\max } 995,796,678,656(\mathrm{sh}), 608,570,498,348 \mathrm{~nm}$. A DME solution of the iridescent material $(0.010 \mathrm{~g}, 0.017 \mathrm{mmol}$ in 3 $\mathrm{mL}$ DME) was added to ferrocenium tetrafluoroborate $(0.005 \mathrm{~g}, 0.017 \mathrm{mmol})$ and the mixture stirred overnight. A turquoise reaction mixture was formed. The solvents were removed in vacuo. MALDI-TOF MS: 1171.4 (23\% $\left.\left[(\mathrm{PcSc})_{2} \mathrm{KH}_{2} \mathrm{O}\right]^{+}\right), 576.2\left(100 \%\left[\mathrm{PcScOH}_{2}\right]^{+}\right)$. 
Reduction of PcScCl (1) with 2 equivalents of $\boldsymbol{K C}_{8}$. $\mathrm{PcScCl}(0.120 \mathrm{~g}, 0.203 \mathrm{mmol})$ was added as a solid to a stirred suspension of $\mathrm{KC}_{8}(0.060 \mathrm{~g}, 0.446 \mathrm{mmol} ; 10 \%$ excess $)$ in $\mathrm{THF}(5 \mathrm{~mL})$. The residue was rinsed into the reaction mixture with THF $(5 \mathrm{~mL})$. The reaction mixture was stirred at ambient temperature overnight. The bright purple reaction mixture was filtered through celite and the solid residue rinsed with THF $(3 \times 5 \mathrm{~mL})$. The solvents were removed from the filtrate in vacuo to leave an iridescent green/gold/purple solid $\left(0.112 \mathrm{~g}, 73 \%\right.$ based on PcScK $\left.(\mathrm{THF})_{4}\right) .{ }^{1} \mathrm{H} \mathrm{NMR:}\left(600 \mathrm{MHz}\right.$, THF- $\left.d_{8}\right)$ $\delta 5.53$ (br s, $1 \mathrm{H}), 5.10$ (br s, 8H), 4.38 (br s, $2 \mathrm{H}), 4.26$ (br s, $1 \mathrm{H}), 4.10$ (br s, 8H) ppm; ${ }^{13} \mathrm{C}\left\{{ }^{1} \mathrm{H}\right\} \mathrm{NMR}\left(150 \mathrm{MHz}, \mathrm{THF}-d_{8}\right) \delta$ 127.7, 124.4, 120.9, 119.1, 118.8 ppm; UV-vis: (THF) $\lambda_{\max }$ 510, $324 \mathrm{~nm}$; Anal. Calcd for $\mathrm{C}_{48} \mathrm{H}_{48} \mathrm{KN}_{8} \mathrm{O}_{4} \mathrm{Sc}: \mathrm{C}_{\text {, } 65.14}$; $\mathrm{H}$, 5.47; N, 12.66. Found C, 63.40; H, 5.83; N, 12.75 .

A THF solution of the recrystallized material $(0.010 \mathrm{~g}, 0.017 \mathrm{mmol}$ in $3 \mathrm{~mL}$ THF $)$ was added to ferrocenium tetrafluoroborate $(0.010 \mathrm{~g}, 0.037 \mathrm{mmol})$ and the mixture stirred overnight. A turquoise reaction mixture was formed. The solvents were removed in vacuo. MALDI-TOF MS: $1315.4 \quad\left(52 \% \quad\left[\left(\mathrm{PcSc}_{2} \mathrm{~K}_{2}\left(\mathrm{H}_{2} \mathrm{O}\right)_{2}\left(\mathrm{BF}_{4}\right)_{2}\right]^{+}\right), \quad 1171.4 \quad(59 \%\right.$ $\left.\left[(\mathrm{PcSc})_{2} \mathrm{KH}_{2} \mathrm{O}\right]^{+}\right), 576.2\left(100 \%\left[\mathrm{PcScOH}_{2}\right]^{+}\right)$. UV-vis: (THF) $\lambda_{\max } 675,605,350 \mathrm{~nm}$.

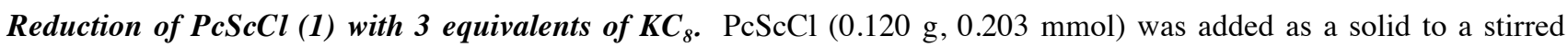
suspension of $\mathrm{KC}_{8}(0.090 \mathrm{~g}, 0.669 \mathrm{mmol} ; 10 \%$ excess $)$ in THF $(5 \mathrm{~mL})$. The residue was rinsed into the reaction mixture with THF $(5 \mathrm{~mL})$. The reaction mixture was stirred at ambient temperature overnight. The bright purple reaction mixture was filtered through celite and the solid residue rinsed with THF $(3 \times 5 \mathrm{~mL})$. The solvents were removed from the filtrate in vacuo to leave an iridescent green/gold/purple solid $\left(0.130 \mathrm{~g}, 83 \%\right.$, based on formation of $\left.(\mathrm{PcSc})_{2} \mathrm{OK}{ }_{4}(\mathrm{THF})_{4}\right)$. ${ }^{1} \mathrm{H} \mathrm{NMR}$ : $\left(600 \mathrm{MHz}, \mathrm{THF}-d_{8}\right) \delta 5.19(\mathrm{~m}, 8 \mathrm{H}, \mathrm{Ar} H), 4.16(\mathrm{~m}, 8 \mathrm{H}, \mathrm{Ar} H) \mathrm{ppm} ;{ }^{13} \mathrm{C}\left\{{ }^{1} \mathrm{H}\right\} \mathrm{NMR}\left(150 \mathrm{MHz}, \mathrm{THF}-d_{8}\right) \delta 155.7,132.5$, 124.1, 118.6 ppm; UV-vis: (THF) $\lambda_{\max } 510,324 \mathrm{~nm}$; Anal. Calcd for $\mathrm{C}_{80} \mathrm{H}_{64} \mathrm{~N}_{16} \mathrm{O}_{5} \mathrm{Sc}_{2}$ : C, 60.98; H, 4.09; N, 14.22. Found C, 62.56; H, 4.09; N, 14.22.

A THF solution of the recrystallized material $(0.010 \mathrm{~g}, 0.017 \mathrm{mmol}$ in $3 \mathrm{~mL}$ THF $)$ was added to ferrocenium tetrafluoroborate $(0.010 \mathrm{~g}, 0.056 \mathrm{mmol})$ and the mixture stirred overnight. A turquoise mixture was formed. The solvents were removed in vacuo. MALDI-TOF MS: $1315.4\left(26 \%\left[(\mathrm{PcSc})_{2} \mathrm{~K}_{2}\left(\mathrm{H}_{2} \mathrm{O}\right)_{2}\left(\mathrm{BF}_{4}\right)_{2}\right]^{+}\right), 1171.4\left(87 \%\left[(\mathrm{PcSc})_{2} \mathrm{KOH}\right]^{+}\right), 576.2$ $\left(100 \%\left[\mathrm{PcScOH}_{2}\right]^{+}\right)$. UV-vis: (THF) $\lambda_{\max } 675,605,350 \mathrm{~nm}$.

Typical reaction for attempted reduction of 3 or 4 with LiBEt $_{3} \mathbf{H}$ or $\boldsymbol{K C}_{8} \cdot \mathrm{LiBEt}_{3} \mathrm{H}\left(0.65 \mathrm{~mL}, 6.50 \mathrm{x} 10^{-3} \mathrm{mmol}\right) \mathrm{was}$ added to a solution of $3\left(2.20 \mathrm{mg}, 1.62 \times 10^{-3} \mathrm{mmol}\right)$ in THF under nitrogen at room temperature. Similarly, to a solution of 3 (4.40 mg, $\left.3.25 \times 10^{-3} \mathrm{mmol}\right)$ in THF was added 5 eq. of $\mathrm{KC}_{8}\left(2.20 \mathrm{mg}, 1.62 \times 10^{-2} \mathrm{mmol}\right)$ at room temperature under nitrogen atmosphere. Both reaction mixtures were stirred for 50 hours, while being monitored by UV-Vis spectroscopy; no isolation of the reduced species were carried out. Analogous reactions for 4 with both $\mathrm{LiBEt}_{3} \mathrm{H}$ and $\mathrm{KC}_{8}$ at various stoichiometries were carried out in a similar fashion and the UV-visible spectra monitored.

$<$ TABLE \#5>

\section{Acknowledgements}

DBL is grateful to NSERC of Canada for generous research support in the form of Discovery and DAS grants. We thank Dr. Eric Ye (SFU) for assistance with acquisition of NMR spectra in non-deuterated THF and Dr. Ania Sergeenko (SFU) for assistance with the X-ray crystallographic data. 


\section{Supporting Information}

Additional UV-visible and ${ }^{1} \mathrm{H}$ NMR spectra of the reduced species; dihedral angle figures and structural diagrams of the PcSc rings for 3 and 4. This material is available at http://www.u-bourgogne.fr/jpp/ Crystallographic data in cif format have been deposited at the Cambridge Crystallographic Data Centre (CCDC) with \# 1959481-1959482. Copies can be obtained on request, free of charge, via www.ccdc.cam.ac.uk/data-request/cif or email: deposit@ccdc.cam.ac.uk

\section{REFERENCES}

1. Lever ABP, Milaeva ER and Speier G, In Phthalocyanines: Properties and Applications, Vol. 3, (Eds.: CC Leznoff, ABP Lever) VCH, New York, 1993; 1.

2. Fukuda T and Kobayashi N, In Handbook of Porphyrin Science, Vol. 9 (Eds.: KM Kadish, KM Smith, R Guilard), World Scientific Press, 2010; 1.

3. Kimura M and Shirai H, In The Porphyrin Handbook: Applications of Phthalocyanines, Vol. 19 (Eds.: KM Kadish, KM Smith, R Guilard) Academic Press, San Diego, 2003; 151.

4. Lever ABP, J. Porph. Phthalocyanines, 1999; 3: 488.

5. Mack J and Stillman MJ, Coord. Chem.Rev., 2001; 219-221: 993.

6. Stillman MJ and Nyokong T, In Phthalocyanines: Properties and Applications (Eds. CC Leznoff, ABP. Lever), VCH, 1989; 1: 133.

7. Zhou W and Leznoff DB, Chem. Commun., 2018; 54: 1829.

8. Zhou W, Thompson JR, Leznoff CC and Leznoff DB, Chem. Eur. J., 2017; 23: 2323.

9. Zhou W, Platel R, Tasso TT, Furuyama T, Kobayashi N and Leznoff DB, Dalton Trans., 2015; 44: 13955.

10. Platel RH, Tasso TT, Zhou W, Furuyama T, Kobayashi N and Leznoff DB, Chem. Commun., 2015; 15: 5986.

11. Wong EWY, Walsby CJ, Storr T and Leznoff DB, Inorg. Chem., 2010; 49: 3343.

12. Hukstadt H, Tutass A, Goldner M, Cornelissen U and Homborg H, Z. Anorg. Allg. Chem., 2001; 627: 485.

13. Lapkina LA, Sakharov SG, Konstantinov NY, Larchenko VE, Gorbunova YG and Tsivadze AY, Russ. J. Inorg. Chem., 2007; 52: 1758.

14. Kirin S and Moskalev PN, Zh. Neorg. Khim., 1971; 16: 3179.

15. Varmuza K, Moresch G and Meller A, Monatsh. Chem., 1974; 105: 327.

16. Arokiyanathan AL and Lakshmipathi S, Inorg. Chim. Acta, 2018; 483: 203.

17. Suzuki A and Oku T, Magnetochemistry, 2017; 3: 21.

18. Lu K, Zhou J, Zhou L, Wang Q, Sun Q and Jena P, App. Phys. Lett., 2011; 99: 163104.

19. Pushkarev VE, Tomilova LG and Nemykin VN, Coord. Chem. Rev., 2016; 319: 110.

20. Hoffmann R, Beier BF, Muetterties EL and Rossi AR, Inorg. Chem., 1977; 16: 511.

21. Kaupp M, Angew. Chem., Intl. Ed., 2001; 40: 3534.

22. Sears J, Cramer R and Boyle T, Acta Cryst.E., 2019; 75: 540.

23. Arnold J, Hoffman CG, Dawson DY and Hollander FJ, Organometallics, 1993; 12: 3645.

24. Brand H and Arnold J, Coord. Chem. Rev., 1995; 140: 137.

25. Smallcombe SH, Patt SL and Keifer PA, J. Magn. Reson. A, 1995; 117: 295. 
26. Simpson AJ and Brown SA, J.Magn. Reson., 2005; 175: 340.

27. Stillman MJ, In Phthalocyanines: Properties and Applications, Vol. 3, (Eds.: C. C. Leznoff, A. B. P. Lever) VCH, New York, 1993; 3: 227.

28. Wong EW and Leznoff DB, J. Porph. Phthalocyanines, 2012; 16: 154.

29. Sewchok, MG; Haushalter, RC; Merloa JS Inorg. Chim. Acta, 1988, 144, 47

30. Konarev DV, Kuzmin AV, Faranov MA, Ishikawa M, Khasanov SS, Nakano Y, Otsuka A, Yamochi H, Saito G and Lyubovskaya RM, Chem. Eur. J., 2015; 21: 1014.

31. Tahiri M, Doppelt P, Fischer J and Weiss R., Inorg. Chim. Acta, 1987; 127: L1.

32. Konarev DV, Zorina LV, Khasanov SS, Litvinov AL, Otsuka A, Yamochi H, Saito G and Lyubovskaya RN, Dalton Trans., 2013; 42: 6810

33. Cissell JA, Vaid TP, DiPasquale AG and Rheingold AL, Inorg. Chem. 2007; 46: 7713.

34. Cissell JA, Vaid TP and Rheingold AL, Inorg. Chem., 2006; 45: 2367.

35. Yoshida T, Zhou W, Furuyama T, Leznoff DB and Kobayashi N, J. Am. Chem. Soc., 2015; 137: 9258.

36. McKearney D, Choua S, Zhou W, Ganga-Sah Y, Ruppert R, Wytko J, Weiss J and Leznoff DB, Inorg. Chem., 2018; 57: 9644.

37. Hung C, Peterson M, Anderson C, Chang TY, Wu G, Scheiner S and Menard G, J. Am. Chem. Soc., $2019 ; 141: 2604$.

38. Schwindt MA, Lejon T and Hegedus LS, Organometallics, 1990; 9: 2814.

39. Hübschle CB, Sheldrick GM and Dittrich B. J. Appl. Crystallogr. 2011; 44: 1281.

40. APEX3S, and SADABS. Madison, WI: Bruker AXS Inc.; 2016.

41. Sheldrick GM. TWINABS, version 2012/1. Göttingen, Germany: University of Göttingen; 1996.

42. Farrugia LJ. J. Appl. Crystallogr. 2016; 30: 565.

43. Fenn TD, Ringe D and Petsko GA, J. Appl. Crystallogr. 2016; 36: 944. 

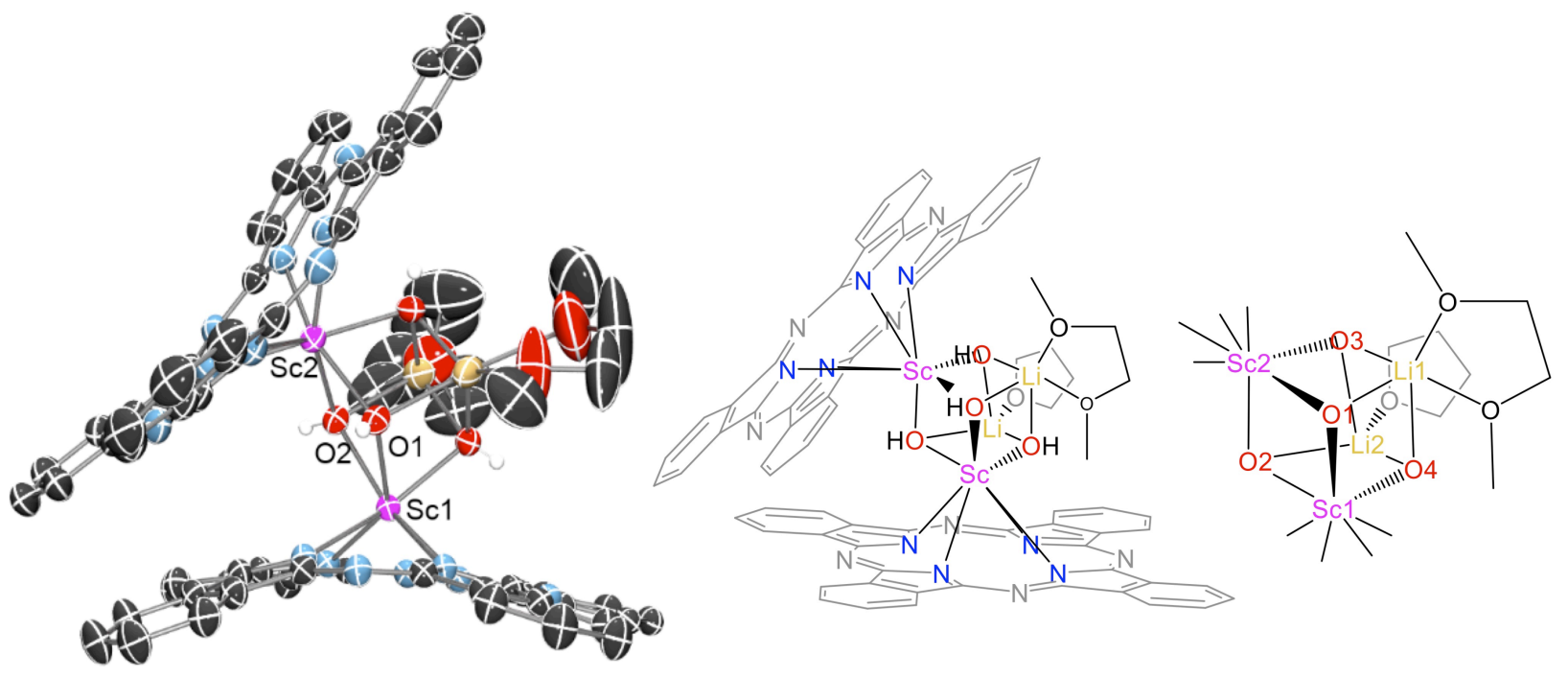

Fig. 1. Solid-state structure of 3; (left) ORTEP plot, with thermal ellipsoids shown at 50\% probability; (right) Chemdraw depiction of 3 and the cubane core, with numbering scheme; hydrogen atoms are omitted for clarity. Colour Scheme: Carbon, Grey; Oxygen, red; Nitrogen, blue; Scandium; magenta; Lithium, yellow. 

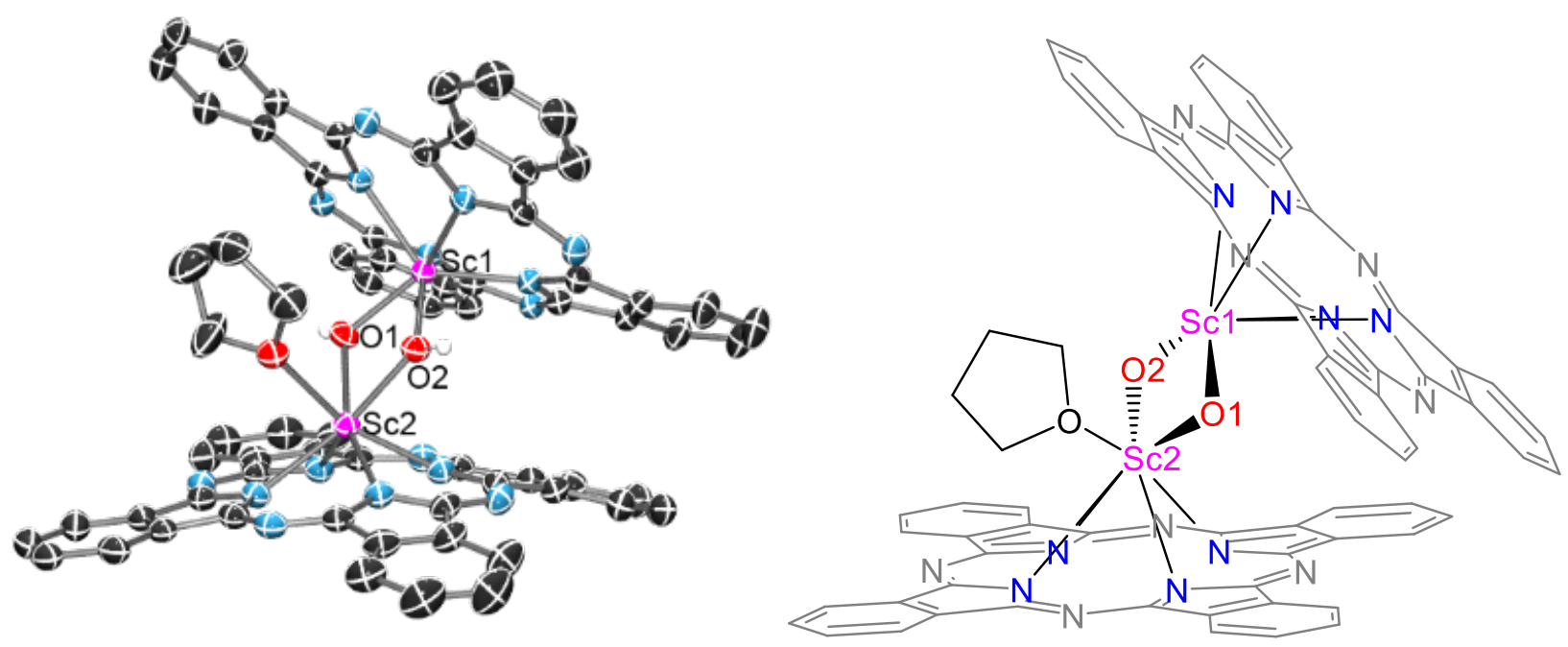

Fig. 2. Solid-state structure of 4; (left) ORTEP plot, with thermal ellipsoids shown at 50\% probability; (right) Chemdraw depiction of 4 with numbering scheme; hydrogen atoms are omitted for clarity). Colour Scheme: Carbon, Grey; Oxygen, red; Nitrogen, blue; Scandium; magenta. 


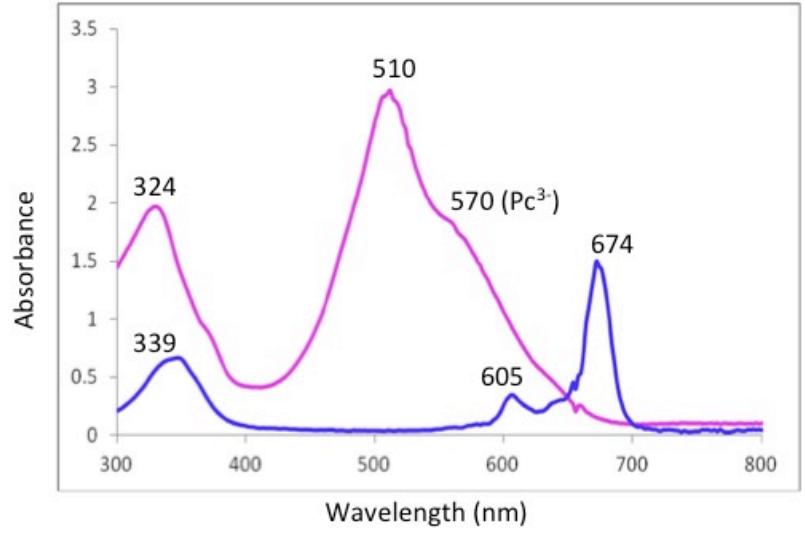

Fig. 3. Absorption spectra of the double ring-reduction of $\mathbf{1}$ with excess $\mathrm{KC}_{8}$ to give $\mathbf{1}^{\mathbf{2}-}$ (pink) and the re-oxidation of $\mathbf{1}^{\mathbf{2}}$ with ferrocenium salts (blue) 


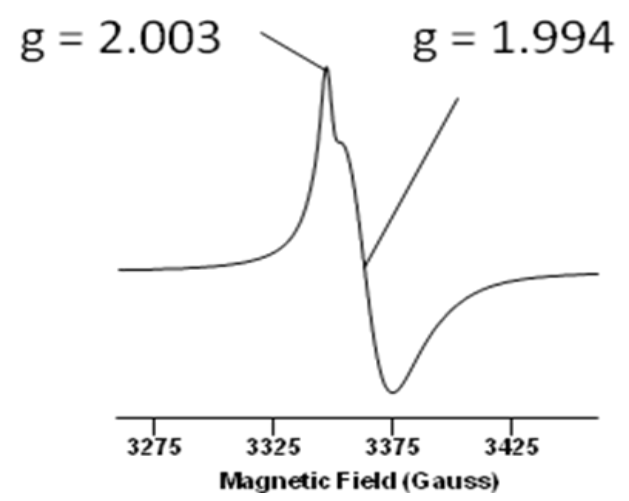

Fig. 4. $\mathrm{EPR}$ spectrum in $\mathrm{THF}$ at $77 \mathrm{~K}$ of the $\mathrm{Pc}^{3-}$-containing products of the reaction of 1 with one equivalent of $\mathrm{KC}_{8}$ 

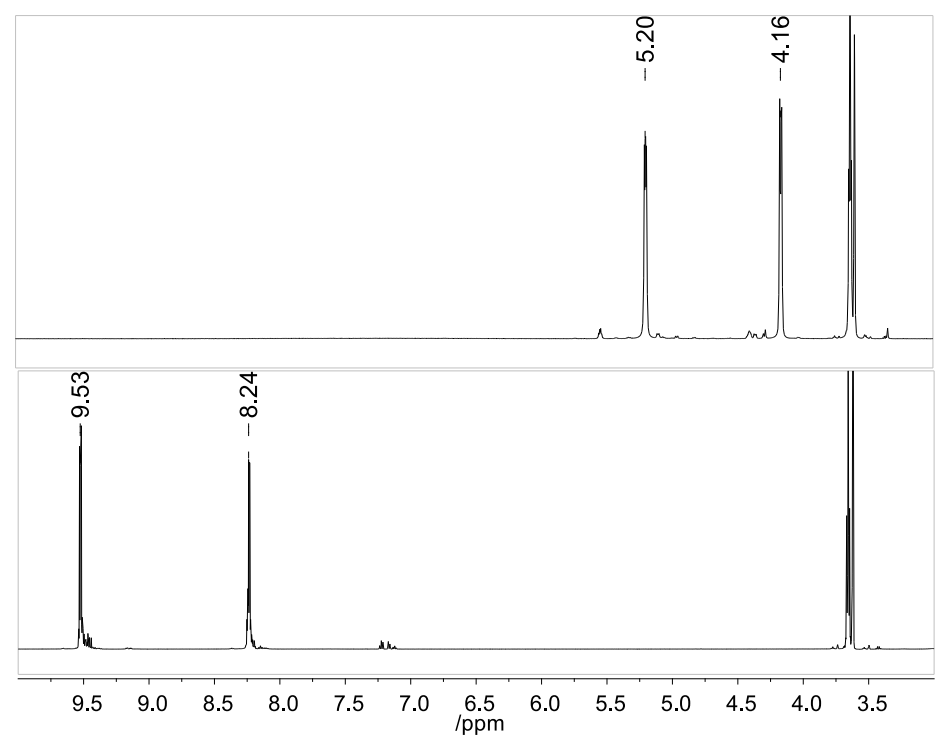

Fig. 5. ${ }^{1} \mathrm{H}$ NMR spectra of (top) $\mathbf{1}^{2-}$ and (bottom) $\mathbf{1}$ in THF- $d_{8}$ 
Table 1. Selected bond lengths $(\AA)$ of $(\mathrm{PcSc})_{2}\left(\mu_{3}-\mathrm{OH}\right)_{4} \mathrm{Li}_{2}(\mathrm{THF})(\mathrm{DME})(\mathbf{3})$

\begin{tabular}{|c|c|c|c|c|c|}
\hline Atom & Atom & Length $/ \AA$ & Atom & Atom & Length/Å \\
\hline Sc1 & $\mathrm{O} 4$ & $2.094(2)$ & Sc2 & N8 & $2.253(3)$ \\
\hline Sc1 & $\mathrm{O} 2$ & $2.181(2)$ & $\mathrm{Sc} 2$ & N2 & $2.267(3)$ \\
\hline Sc1 & $\mathrm{O} 1$ & $2.225(2)$ & Sc2 & $\mathrm{N} 4$ & $2.281(3)$ \\
\hline $\mathrm{Sc1}$ & N14 & $2.245(3)$ & $\mathrm{Sc} 2$ & $\mathrm{Li} 2$ & $3.055(6)$ \\
\hline $\mathrm{Sc1}$ & N12 & $2.257(3)$ & Sc2 & Li1 & $3.142(6)$ \\
\hline Sc1 & N10 & $2.263(2)$ & $\mathrm{O} 1$ & Li1 & $2.093(8)$ \\
\hline $\mathrm{Sc1}$ & N16 & $2.280(2)$ & $\mathrm{O} 2$ & $\mathrm{Li} 2$ & $1.996(7)$ \\
\hline Sc1 & $\mathrm{Li} 2$ & $3.032(6)$ & $\mathrm{O} 3$ & Li2 & $1.878(7)$ \\
\hline Sc1 & Li1 & $3.116(6)$ & $\mathrm{O} 3$ & Li1 & $1.913(7)$ \\
\hline Sc1 & $\mathrm{Sc} 2$ & $3.5516(8)$ & O4 & Li1 & $1.913(7)$ \\
\hline $\mathrm{Sc} 2$ & $\mathrm{O} 3$ & $2.130(3)$ & $\mathrm{O} 4$ & $\mathrm{Li} 2$ & $1.920(7)$ \\
\hline $\mathrm{Sc} 2$ & $\mathrm{O} 1$ & $2.169(2)$ & O6 & Li1 & $1.942(7)$ \\
\hline $\mathrm{Sc} 2$ & $\mathrm{O} 2$ & $2.196(2)$ & O7 & Li1 & $2.374(9)$ \\
\hline $\mathrm{Sc} 2$ & N6 & $2.246(3)$ & & & \\
\hline
\end{tabular}


Table 2. Selected bond angles $\left({ }^{\circ}\right)$ of $(\mathrm{PcSc})_{2}\left(\mu_{3}-\mathrm{OH}\right)_{4} \mathrm{Li}_{2}(\mathrm{THF})(\mathrm{DME})(3)$

\begin{tabular}{|c|c|c|c|c|c|c|c|}
\hline Atom & Atom & Atom & Angle $/^{\circ}$ & Atom & Atom & Atom & Angle $/^{\circ}$ \\
\hline $\mathrm{O} 4$ & Sc1 & $\mathrm{O} 2$ & $79.51(10)$ & $\mathrm{O} 3$ & Sc2 & O1 & 77.72(10) \\
\hline $\mathrm{O} 4$ & Sc1 & $\mathrm{O} 1$ & $78.62(9)$ & $\mathrm{O} 3$ & Sc2 & $\mathrm{O} 2$ & $77.66(9)$ \\
\hline $\mathrm{O} 2$ & Sc1 & $\mathrm{O} 1$ & $71.09(8)$ & $\mathrm{O} 1$ & Sc2 & $\mathrm{O} 2$ & $71.87(8)$ \\
\hline O4 & Sc1 & N14 & $95.26(10)$ & $\mathrm{O} 3$ & Sc2 & N6 & $82.52(11)$ \\
\hline $\mathrm{O} 2$ & Sc1 & N14 & $156.54(9)$ & $\mathrm{O} 1$ & $\mathrm{Sc} 2$ & N6 & $157.65(10)$ \\
\hline O1 & Sc1 & N14 & $85.47(9)$ & $\mathrm{O} 2$ & Sc2 & N6 & $93.90(9)$ \\
\hline O4 & Sc1 & N12 & $159.02(10)$ & $\mathrm{O} 3$ & $\mathrm{Sc} 2$ & $\mathrm{~N} 8$ & $78.50(10)$ \\
\hline $\mathrm{O} 2$ & Sc1 & N12 & $100.51(9)$ & $\mathrm{O} 1$ & Sc2 & $\mathrm{N} 8$ & $109.09(9)$ \\
\hline O1 & Sc1 & N12 & $81.56(9)$ & $\mathrm{O} 2$ & Sc2 & N8 & $155.29(10)$ \\
\hline N14 & Sc1 & N12 & $76.30(9)$ & N6 & Sc2 & N8 & $76.62(10)$ \\
\hline $\mathrm{O} 4$ & Sc1 & N10 & $123.49(10)$ & $\mathrm{O} 3$ & $\mathrm{Sc} 2$ & N2 & $138.26(11)$ \\
\hline $\mathrm{O} 2$ & Sc1 & N10 & $79.02(9)$ & $\mathrm{O} 1$ & $\mathrm{Sc} 2$ & $\mathrm{~N} 2$ & $81.57(10)$ \\
\hline O1 & Sc1 & N10 & $138.73(9)$ & $\mathrm{O} 2$ & $\mathrm{Sc} 2$ & N2 & $128.75(10)$ \\
\hline N14 & Sc1 & N10 & $121.67(9)$ & N6 & $\mathrm{Sc} 2$ & N2 & $120.53(10)$ \\
\hline N12 & Sc1 & N10 & $76.55(9)$ & N8 & $\mathrm{Sc} 2$ & N2 & $74.67(11)$ \\
\hline $\mathrm{O} 4$ & Sc1 & N16 & $76.27(9)$ & $\mathrm{O} 3$ & $\mathrm{Sc} 2$ & $\mathrm{~N} 4$ & $145.70(11)$ \\
\hline $\mathrm{O} 2$ & Sc1 & N16 & $123.72(9)$ & $\mathrm{O} 1$ & Sc2 & $\mathrm{N} 4$ & $117.93(10)$ \\
\hline $\mathrm{O} 1$ & Sc1 & N16 & $147.13(9)$ & $\mathrm{O} 2$ & Sc2 & $\mathrm{N} 4$ & $79.06(9)$ \\
\hline N14 & Sc1 & N16 & $76.12(9)$ & N6 & Sc2 & $\mathrm{N} 4$ & $74.31(10)$ \\
\hline N12 & Sc1 & N16 & $119.00(9)$ & $\mathrm{N} 8$ & Sc2 & $\mathrm{N} 4$ & $118.89(10)$ \\
\hline N10 & Sc1 & N16 & $73.77(9)$ & N2 & Sc2 & N4 & $75.98(11)$ \\
\hline
\end{tabular}


Table 3. Selected bond lengths $(\AA)$ of $(\mathrm{PcSc})_{2}(\mu-\mathrm{OH})_{2}(\mathrm{THF})(\mathbf{4})$

\begin{tabular}{|c|c|c|c|c|c|}
\hline Atom & Atom & Length/Å & Atom & Atom & Length/Ä \\
\hline Sc1 & $\mathrm{O} 2$ & $2.056(3)$ & O1 & Sc2 & $2.106(3)$ \\
\hline Sc1 & $\mathrm{O} 1$ & $2.084(3)$ & $\mathrm{O} 2$ & Sc2 & $2.129(3)$ \\
\hline Sc1 & N12 & $2.177(3)$ & $\mathrm{Sc} 2$ & N4 & $2.219(3)$ \\
\hline $\mathrm{Sc1}$ & N16 & $2.185(3)$ & $\mathrm{Sc} 2$ & N6 & $2.249(3)$ \\
\hline Scl & N14 & $2.198(3)$ & $\mathrm{Sc} 2$ & N8 & $2.262(3)$ \\
\hline Sc1 & N10 & $2.199(3)$ & $\mathrm{Sc} 2$ & N2 & $2.220(3)$ \\
\hline Sc1 & $\mathrm{Sc} 2$ & $3.3713(9)$ & $\mathrm{Sc} 2$ & O5 & $2.346(3)$ \\
\hline
\end{tabular}


Table 4. Selected bond angles $\left(^{\circ}\right)$ of $(\mathrm{PcSc})_{2}(\mu-\mathrm{OH})_{2}(\mathrm{THF})(4)$

\begin{tabular}{|c|c|c|c|c|c|c|c|}
\hline Atom & Atom & Atom & Angle ${ }^{\circ}$ & Atom & Atom & Atom & Angle $/^{\circ}$ \\
\hline $\mathrm{O} 2$ & Sc1 & O1 & $72.75(10)$ & $\mathrm{O} 1$ & $\mathrm{Sc} 2$ & N2 & $156.72(11)$ \\
\hline $\mathrm{O} 2$ & Sc1 & N12 & $125.83(1)$ & $\mathrm{O} 2$ & $\mathrm{Sc} 2$ & $\mathrm{~N} 2$ & $85.85(11)$ \\
\hline $\mathrm{O} 1$ & $\mathrm{Sc} 1$ & N12 & $89.13(11)$ & $\mathrm{N} 4$ & $\mathrm{Sc} 2$ & N2 & $78.14(11)$ \\
\hline $\mathrm{O} 2$ & $\mathrm{Sc} 1$ & N16 & $98.01(11)$ & $\mathrm{O} 1$ & $\mathrm{Sc} 2$ & N6 & $77.67(10)$ \\
\hline O1 & Sc1 & N16 & $131.66(1)$ & $\mathrm{O} 2$ & $\mathrm{Sc} 2$ & N6 & $137.31(11)$ \\
\hline N12 & Sc1 & N16 & $129.28(1)$ & N4 & $\mathrm{Sc} 2$ & N6 & $76.31(11)$ \\
\hline $\mathrm{O} 2$ & Sc1 & N14 & $87.34(11)$ & N2 & Sc2 & N6 & $122.48(11)$ \\
\hline $\mathrm{O} 1$ & Sc1 & N14 & $143.49(11)$ & $\mathrm{O} 1$ & $\mathrm{Sc} 2$ & $\mathrm{~N} 8$ & $123.64(11)$ \\
\hline N12 & Sc1 & N14 & $77.98(11)$ & $\mathrm{O} 2$ & $\mathrm{Sc} 2$ & N8 & 147.21(11) \\
\hline N16 & Sc1 & N14 & $80.27(11)$ & $\mathrm{N} 4$ & Sc2 & N8 & $121.56(11)$ \\
\hline $\mathrm{O} 2$ & Sc1 & N10 & $143.27(10)$ & $\mathrm{N} 2$ & Sc2 & N8 & $76.28(12)$ \\
\hline $\mathrm{O} 1$ & Sc1 & N10 & $82.77(11)$ & N6 & Sc2 & N8 & $74.99(11)$ \\
\hline N12 & Sc1 & N10 & $79.53(11)$ & $\mathrm{O} 1$ & $\mathrm{Sc} 2$ & O5 & $80.34(11)$ \\
\hline N16 & Sc1 & N10 & $78.07(11)$ & $\mathrm{O} 2$ & Sc2 & O5 & $80.12(10)$ \\
\hline N14 & Sc1 & N10 & $126.91(11)$ & N4 & Sc2 & O5 & $159.58(11)$ \\
\hline N2 & $\mathrm{Sc} 2$ & O5 & $95.55(11)$ & N6 & $\mathrm{Sc} 2$ & O5 & $122.47(11)$ \\
\hline $\mathrm{O} 1$ & $\mathrm{Sc} 2$ & $\mathrm{O} 2$ & $70.87(10)$ & N8 & $\mathrm{Sc} 2$ & O5 & $74.61(10)$ \\
\hline $\mathrm{O} 1$ & $\mathrm{Sc} 2$ & $\mathrm{~N} 4$ & $97.73(11)$ & $\mathrm{O} 2$ & Sc2 & $\mathrm{N} 4$ & $80.06(11)$ \\
\hline Sc1 & $\mathrm{O} 1$ & $\mathrm{Sc} 2$ & $107.15(12)$ & Sc1 & $\mathrm{O} 2$ & $\mathrm{Sc} 2$ & $107.30(12)$ \\
\hline
\end{tabular}


Table 5. Summary of Crystallographic Data for $\mathbf{3}$ and $\mathbf{4}$

\begin{tabular}{|c|c|c|}
\hline Complex & 3 & 4 \\
\hline Empirical formula & $\mathrm{C}_{72} \mathrm{H}_{46} \mathrm{Li}_{2} \mathrm{~N}_{16} \mathrm{O}_{7} \mathrm{Sc}_{2}$ & $\mathrm{C}_{153} \mathrm{H}_{94} \mathrm{~N}_{32} \mathrm{O}_{10} \mathrm{Sc}_{4}$ \\
\hline Formula weight & 1351.05 & 2720.44 \\
\hline Temperature/K & $150(2)$ & $150(2)$ \\
\hline Crystal system & triclinic & triclinic \\
\hline Space group & $\mathrm{P}-1$ & $\mathrm{P}-1$ \\
\hline $\mathrm{a} / \AA ̊$ & $12.8317(9)$ & $16.9974(5)$ \\
\hline $\mathrm{b} / \AA$ & $14.3558(10)$ & $18.8764(6)$ \\
\hline $\mathrm{c} / \AA$ & $19.7923(14)$ & $22.8015(7)$ \\
\hline$\alpha /^{\circ}$ & $101.895(4)$ & $76.369(2)$ \\
\hline$\beta /^{\circ}$ & $102.518(4)$ & $75.714(2)$ \\
\hline$\gamma / /^{\circ}$ & $109.385(4)$ & $68.049(2)$ \\
\hline Volume $/ \AA^{3}$ & $3200.8(4)$ & $6491.4(4)$ \\
\hline $\mathrm{Z}$ & 2 & 2 \\
\hline$\varrho_{\text {calc }} \mathrm{g} / \mathrm{cm}^{3}$ & 1.402 & 1.392 \\
\hline$\mu / \mathrm{mm}^{-1}$ & 2.400 & 2.354 \\
\hline $\mathrm{F}(000)$ & 1388.0 & 2800.0 \\
\hline Crystal size $/ \mathrm{mm}^{3}$ & $0.286 \times 0.155 \times 0.116$ & $0.289 \times 0.194 \times 0.067$ \\
\hline Radiation & $\mathrm{CuK} \alpha(\lambda=1.54178)$ & $\operatorname{CuK} \alpha(\lambda=1.54178)$ \\
\hline $2 \theta$ range for data collection $/{ }^{\circ}$ & 4.798 to 133.676 & 4.05 to 133.39 \\
\hline Index ranges & $\begin{array}{l}-15 \leq \mathrm{h} \leq 15,-17 \leq \mathrm{k} \leq 17,-23 \leq 1 \leq \\
23\end{array}$ & $-20 \leq \mathrm{h} \leq 20,-22 \leq \mathrm{k} \leq 22,-27 \leq 1 \leq 25$ \\
\hline Reflections collected & 48134 & 73338 \\
\hline Independent reflections & $\begin{array}{l}10980\left[\mathrm{R}_{\text {int }}=0.0345, \mathrm{R}_{\text {sigma }}=\right. \\
0.0295]\end{array}$ & $22198\left[\mathrm{R}_{\mathrm{int}}=0.0646, \mathrm{R}_{\text {sigma }}=0.0579\right]$ \\
\hline Data/restraints/parameters & $10980 / 1121 / 929$ & $22198 / 2188 / 1863$ \\
\hline Goodness-of-fit on $\mathrm{F}^{2}$ & 1.025 & 1.023 \\
\hline Final $R$ indexes $[\mathrm{I}>=2 \sigma(\mathrm{I})]$ & $\mathrm{R}_{1}=0.0630, \mathrm{wR}_{2}=0.1778$ & $\mathrm{R}_{1}=0.0641, \mathrm{wR}_{2}=0.1742$ \\
\hline Final $\mathrm{R}$ indexes [all data] & $\mathrm{R}_{1}=0.0687, \mathrm{wR}_{2}=0.1852$ & $\mathrm{R}_{1}=0.0897, \mathrm{wR}_{2}=0.1976$ \\
\hline Largest diff. peak/hole / e $\AA^{-3}$ & $1.75 /-0.78$ & $1.79 /-0.70$ \\
\hline
\end{tabular}




\section{Synthesis, structure and reduction chemistry of monophthalocyanine scandium hydroxides}

Yumeela Ganga-Sah, Elahe Tajbakhsh, Rachel H. Platel, Wen Zhou and Daniel B. Leznoff*

Phthalocyanine scandium(III) hydroxide complexes were prepared and structurally characterized from $\mathrm{PcScCl}$ and show a range of structures in the solid state, depending on solvent of crystallization and accompanying alkali metal cation.

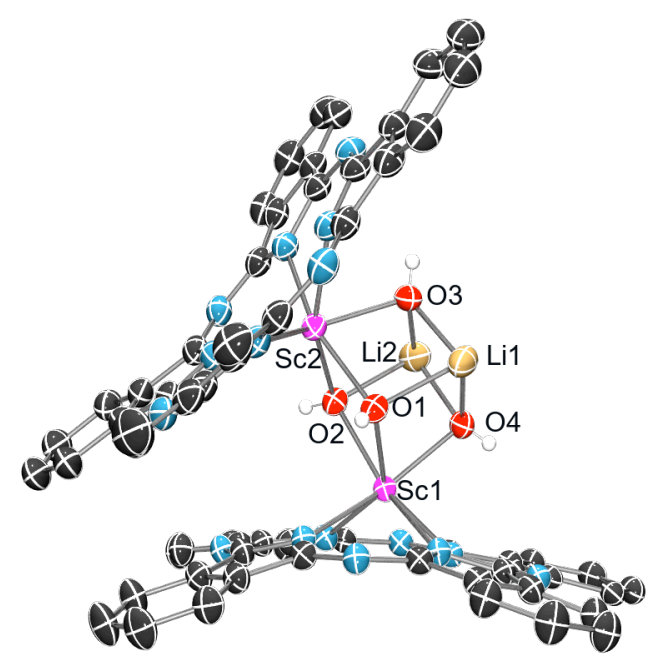

